Original Article

\title{
OPTIMIZATION OF EXTRACTION PARAMETERS OF ETHANOL EXTRACTS OF PROPOLIS SAMPLES USING ARTIFICIAL NEURAL NETWORK AND MOTH-FLAME OPTIMIZATION ALGORITHM
}

\author{
Ayșenur Gurgen ${ }^{1}$ \\ Huseyin Serencam² \\ Yakup Kara \\ Zehra Can $^{4 *}$ \\ Sibel Yıldı $Z^{1}$ \\ ${ }^{1}$ Karadeniz Technical University, Faculty of Forest, Forest Industry Engineering, \\ Trabzon, Turkey \\ ${ }^{2}$ Trabzon University, School of Applied Sciences, Gastronomy and Culinary Arts, \\ Trabzon, Turkey \\ ${ }^{3}$ Karadeniz Technical University, Faculty of Science, Department of Chemistry, \\ Trabzon, Turkey \\ ${ }^{4}$ Faculty of Applied Sciences, Bayburt University, 69000, Bayburt, Turkey \\ *corresponding author: zehracan61@gmail.com \\ Received: 16 June 2020; accepted: 08 July 2021
}

A bstract

In this study, the optimum values of propolis ethanol extracts parameters were determined with the use of single and multi-objective optimization procedures. The euclidean distance approach was used in the multi-objective optimization process. Firstly, propolis was extracted using water with ethanol contents $40,50,60,70$ and $80 \%$ for $8,10,12$, 16,20 and $24 \mathrm{~h}$. Then, total phenolic content (TPC) and ferric reducing antioxidant power (FRAP) activities of all extracts were determined. With the obtained data a prediction model was produced with the use of artificial neural networks (ANN), and optimization was performed using a moth-flame (MFO) algorithm. The best prediction models for the TPC and FRAP were observed in 2-5-1 and 2-5-1 network architecture with the mean absolute percentage error (MAPE) values, 5.126 and $2.451 \%$, respectively. For maximum TPC, the extraction parameters were determined as ethanol content $57.5 \%$ and extraction time $13.56 \mathrm{~h}$. To maximize FRAP, the optimized extraction parameters were ethanol content $72.03 \%$ and extraction time $18.04 \mathrm{~h}$. The optimum extraction conditions for both maximum values of the studied assays were ethanol content $70.03 \%$ and extraction time $16.93 \mathrm{~h}$. The study concluded that the integrated ANN and MFO algorithm system can be used in single and multi-objective optimization of extraction parameters. The established optimization model can save time, money, labor and energy.

Key words: artificial neural network, extraction parameters, modelling, optimization, propolis

\section{INTRODUCTION}

Propolis is a resin material that honeybees (Apis mellifera) collect from living plants, mix with saliva enzymes ( $\beta$-glucosidase) and use to seal parts of the hive, fill gaps and mummify carcasses of external invasive insects (Bankova et al., 2000). It is also considered to be a functional and nutraceutical ingredient in food products. Furthermore, propolis is used to line the chambers and alveoli where the queens lay eggs. Because of its pharmacological properties, many ancient civilizations used it to produce medicine (ladnut et al., 2019; Rivero-Cruz et al., 2020).

Propolis has attracted the attention of researchers in recent decades due to its biological and pharmacological properties. It has been 
shown to be non-toxic to humans and mammals except for in very large doses. For this reason, propolis has been used in the preservation of food products (seafood, juice, fish, meat, soft drinks and fruits), in development of veterinary medicine and cosmetics and drugs (Casquete et al., 2016; Jonaidi-Jafari et al., 2018).

More than three-hundred chemical compounds have been identified in different propolis samples (Bankova et al., 2000). The presence of aldehydes, terpenoids, flavonoids, chalcones, esters, aliphatic and phenolic acids, amino acids and aromatic acids have been highlighted in propolis. The most common phenolic compounds are Artepilin C, galangin, $p$-coumaric acid, caffeic acid, pinocembrin, acid benzoic, caffeic acid phenethyl ester and chrysin. Flavanones, flavonols, flavones and dihydroflavonols are

Comparison of some propolis extraction optimization research with the study

Table 1.

\begin{tabular}{|c|c|c|c|}
\hline Previous study & Input variables & Output variables & Optimization method \\
\hline Yingjuan et al. (2007) & $\begin{array}{l}\text { Ethanol concentration } \\
\text { Extracting time } \\
\text { Extracting power } \\
\text { Ratio of liquid to propolis }\end{array}$ & Flavones & $\begin{array}{l}\text { Response Surface } \\
\text { Methodology (RSM) }\end{array}$ \\
\hline Wang et al. (2009) & $\begin{array}{c}\text { Ethanol concentration } \\
\text { Ratio of liquid } \\
\text { The holding time of pressure } \\
\text { Pressure to propolis }\end{array}$ & Flavones & RSM \\
\hline $\begin{array}{l}\text { Kim et al. } \\
\text { (2009) }\end{array}$ & $\begin{array}{l}\text { Ethanol concentration } \\
\text { Extraction time }\end{array}$ & $\begin{array}{c}\text { Total polyphenol } \\
\text { content (TPC) } \\
\text { Total flavonoid content } \\
\text { (TFC) }\end{array}$ & RSM \\
\hline Li et al. (2012) & $\begin{array}{c}\text { Microwave treatment time } \\
\text { Microwave power } \\
\text { Ethanol concentration } \\
\text { Temperature } \\
\text { Time } \\
\text { Solvent-to-solid }\end{array}$ & Total flavonoid yield & RSM \\
\hline $\begin{array}{l}\text { Yuan et al. } \\
\text { (2013) }\end{array}$ & $\begin{array}{l}\text { Ratio of lipid to drug } \\
\text { Ratio of soybean phospholipid } \\
\text { to cholesterol } \\
\text { Speed of injection }\end{array}$ & $\begin{array}{l}\text { Propolis flavonoids } \\
\text { liposome (PFL) }\end{array}$ & RSM \\
\hline $\begin{array}{l}\text { Zhao et al. } \\
\text { (2012) }\end{array}$ & $\begin{array}{c}\text { Extraction time } \\
\text { Ethanol concentration } \\
\text { Solid-liquid ratio } \\
\text { Distilling frequency } \\
\text { Distilling temperature }\end{array}$ & $\begin{array}{c}\text { Extraction ratio } \\
\text { TFC }\end{array}$ & RSM \\
\hline Oldoni et al. (2015) & $\begin{array}{c}\text { Ethanol ratio } \\
\text { Temperature } \\
\text { Time }\end{array}$ & $\begin{array}{l}\text { TPC } \\
\text { DPPH }\end{array}$ & $2^{3}$ factorial design \\
\hline Nichitoi et al. (2019) & $\begin{array}{c}\text { Particle size } \\
\text { Solvent type (ethanolic } \\
\text { aqueous) } \\
\text { Extraction duration }\end{array}$ & $\begin{array}{c}\text { TPC } \\
\text { TFC } \\
\text { Antioxidant } \\
\text { capacity }\end{array}$ & $\begin{array}{c}\text { Partial Least Squares } \\
\text { Regression }\end{array}$ \\
\hline Our study & $\begin{array}{l}\text { Ethanol content } \\
\text { Extraction time }\end{array}$ & $\begin{array}{c}\text { TPC (Single objective) } \\
\text { FRAP activities (Single } \\
\text { objective) } \\
\text { TPC and FRAP (Multi-ob- } \\
\text { jective) }\end{array}$ & ANN and MFO \\
\hline
\end{tabular}


also found in samples (Rivero-Cruz et al., 2020). Propolis generally contains plant resins and balsams (approximately 50\%) composed of phenolic acids and flavonoids, pollen (5\%), essential oils (10\%), waxes (up to $30 \%$ ) and different organic compounds (5\%) including vitamins (B1, B2, B3, and B6), benzoic acid, iron (Fe) and zinc ( $\mathrm{Zn})$, esters, lactones, fatty acids, quinones, steroids, ketones, and sugars as well as natural pigments like carotenoids and chlorophyll (KIhar et al., 2019). Such compounds as propolis with antioxidant capacity inhibit the oxidative stress resulting from the presence of free radicals in the organism.

The chemical composition of propolis depends on the flora of the region, the season, the geography, plant origins and the bee species. Moreover, the composition of propolis may vary quantitatively and qualitatively depending on different plant sources, its harvest type and harvesting season (Moreno et al., 2000). In addition, extraction parameters affect the bio-active properties of propolis as with almost all natural materials. Studying the activity of the studied material under different extraction conditions provides useful information for the researchers. Optimizing extraction parameters is most efficient way to maximize -or minimizetargeted activity.

Comparisons of some propolis extraction optimization studies with this study are shown in Tab. 1. In the previous studies, such inputs as ethanol concentration, extraction temperature and extraction time were used to optimize extraction propolis parameters for different output variables including flavones (Yingjuan et al., 2007; Wang et al., 2009), TPC, TFC (Kim et al., 2009; Nichitoi et al., 2019), total flavonoid yield (Li et al., 2012), propolis flavonoids liposome (Yuan et al., 2013), extraction ratio (Zhao et al., 2012) and antioxidant capacity (Oldoni et al., 2015; Nichitoi et al., 2019). When the studies were evaluated, it was shown that generally the response surface method (RSM), one of the deterministic calculation methods, has been used for optimization of extraction parameters studies. Compared with traditional methods, artificial neural networks (ANN) tolerate inaccurate or incomplete data and relate unrelated information (Jothiprakash \& Garg, 2009), because a fixed formula is not used in the modeling process. In this study, extraction parameters were predicted by ANN

ANN, an artificial intelligence technique, has been observed to be much better at predicting compared to traditional methods. For the first time, in this study the parameters of ethanolic extracts of propolis samples will be modeled and optimized with the ANN and MFO algorithm method, respectively. The integrated ANN and MFO algorithm system are thought to be used for single and multi-objective optimization of extraction parameters saving time, chemical, cost and effort.

\section{MATERIAL AND METHODS}

\section{Material and extraction}

Five samples of propolis were obtained from different beekeepers in Turkey's Bayburt province and prepared in different solutions. Each sample weighing 5 grams were diluted with ethanol contents of $40,50,60,70$ and $80 \%$ (Heidolph Promax 2020, Schwabach, Germany) and digested for 8, 10, 12, 16, 20 and 24 hours at room temperature. Afterwards, the samples were filtered (Whatman \#2 paper) and particles were removed. The final volume of the solution was adjusted with different proportions of an ethanol solvent.

\section{Total phenolic content (TPC)}

The total phenolic content of the propolis samples were measured according to the Folin-Ciocaltaeu method suggested by Slinkard \& Singleton (1977). First, $20 \mu \mathrm{L}$ of the sample was added into a test tube containing $400 \mu \mathrm{L}$ $0.5 \mathrm{~N}$ of Folin-Ciocalteu's reagent, $680 \mu \mathrm{L}$ of distilled water and $400 \mu \mathrm{L}$ of $10 \% \mathrm{Na}_{2} \mathrm{CO}_{3}$ and then vortexed. Next, the mixture was incubated at room temperature for $2 \mathrm{~h}$. The absorbance of blue coloration was measured at $760 \mathrm{~nm}$ against a blank sample. The polyphenol concentration in the samples was derived from a standard curve of absorbance of gallic acid concentrations, ranging from 0.03125 to $1.0 \mathrm{mg} / \mathrm{mL}$. 
All measurements were performed in triplicate. Gallic acid was used as the standard, and TPC results were expressed as milligram gallic acid equivalent per gram (mg GAE/g).

\section{Total antioxidant activity: FRAP assay}

Total antioxidant activity was assayed with the original method by Benzie \& Strain (1996), which they based on the reduction of an iron 2,4,6-tripyridyl-s-triazine complex (Fe ${ }^{3+}$-TPTZ) to its ferrous, colored form (Fe $\left.\mathrm{Fe}^{2+}-\mathrm{TPTZ}\right)$ in the presence of antioxidants. The FRAP reagent contained acetate buffer (300 $\mu \mathrm{M}, \mathrm{pH}$ 3.6), a solution of $10 \mu \mathrm{M}$ TPTZ in $40 \mu \mathrm{M} \mathrm{HCl}$ and 20 $\mu \mathrm{M} \mathrm{FeCl}{ }_{3}$. The reagent was prepared daily. 100 $\mu \mathrm{L}$ of the extract samples were mixed with 3 $\mathrm{mL}$ of the FRAP reagent. The reaction mixture's absorbance was measured by spectrophotometrically at $593 \mathrm{~nm}$ after a four-minute incubation. The results were expressed FRAP as $\mu \mathrm{mol}$ $\mathrm{FeSO}_{4} 7 \mathrm{H}_{2} \mathrm{O} / \mathrm{g}$ ).

\section{Statistical measurements}

All experiments were carried out three times. The obtained data were recorded as means \pm standard deviations and analyzed through the use of a statistical package for social sciences (SPSS version 21.0). TPC and FRAP activities of extracts was performed with the multivariate analysis of variance. Mean values were compared with "Duncan" homogeneity groups.
The level of significance was set at $5 \%(p<0.05)$.

\section{Modelling and optimization}

The obtained data from the experimental studies were used to produce a prediction model with the use of ANN. The optimization procedure was then applied with the use the MFO algorithm.

\section{Artificial neural network (ANN)}

Artificial neural networks (ANN) are flexible and non-parametric modeling tools (Chi \& Tang, 2005). These networks are a method developed through the simulation of the brain's cognitive learning process (Haykin, 1994) and have been found to be highly effective in such complex problems as prediction, classification and clustering.

ANN contains many linked nerve cells; a typical neuron input is the output of another neuron, which are transmitted through connections. The combination of nerve cells is not random. Generally, cells come together in three layers and parallel in each layer to reveal the network. ANN usually contains an input layer, one or more hidden layers and an output layer. These connections are called synapses in biology and each synaptic link force is indicated by numerical values called weights (Smith, 1994).

The complex systems are the most important feature of neural networks which produce a

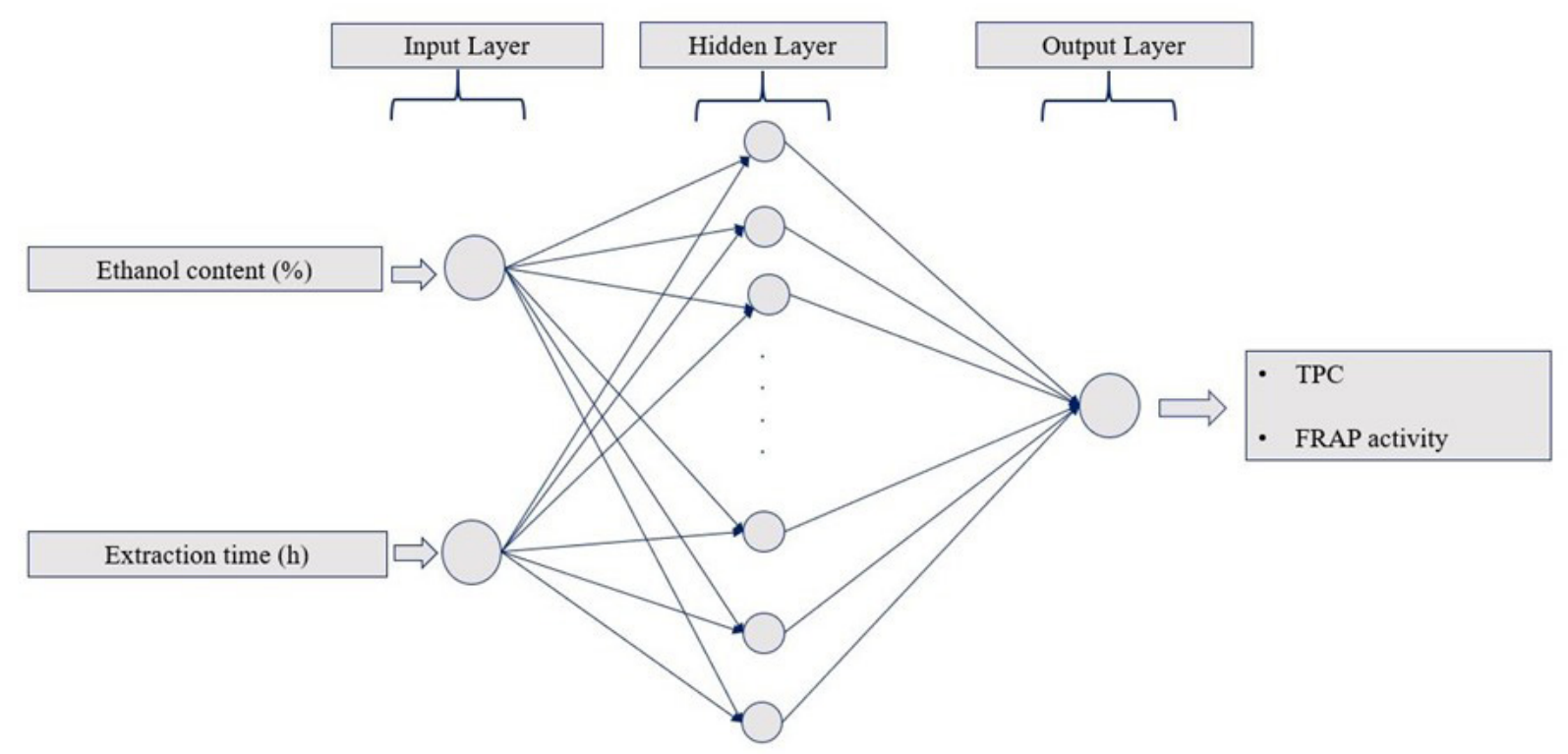

Fig. 1. The layers of this study. 
response by learning from the sample based on the past knowledge for complex problem. ANN creates a high number of connections between process layers, called the input layer, output layer, and hidden layer(s), to solve certain problems. The layers of this study are shown at Fig. 1.

In the study, ethanol content and extraction time were used as input data, while TPC and FRAP activity of the extracts were used separately as output data. Twenty different hidden neurons (from 1 to 20) and the Levenberg Marquardt and Scaled Conjugate Gradient algorithms were used to obtain the powerful prediction model. Consequently, forty potential models were obtained at the end of the study for each output. All data was divided into three groups: $75 \%$, $10 \%$ and $15 \%$ of data to be used for training, validation and testing, respectively. The logistic sigmoid function was selected as a hidden layer activation function, and a linear transfer function was used as output layer activation function. The performance goal for the training and maximum validation error epochs were set as $10^{-2}$ and 50 , respectively.

Mean square error (MSE) and mean absolute percent error (MAPE) used to determine ANN model performance are shown in Equations 1 and 2 , respectively.

$$
\begin{aligned}
& M S E=\frac{1}{n} \sum_{i=1}^{n}\left(e_{i}-p_{i}\right)^{2} \\
& M A P E=\frac{1}{n} \sum\left|\frac{e_{i}-p_{i}}{e_{i}}\right| * 100
\end{aligned}
$$

where $e$ is the experimental result, $p$ is the prediction result and $n$ is the number of samples.

\section{Moth-flame optimization (MFO) algorithm}

As the variety and complexity of engineering problems increases, researchers are constantly developing and adding new optimization methods to the literature. They have developed optimization algorithms by imitating the events or living things which inspire them. One such optimization algorithms is the Moth-Flame Optimization (MFO) developed by Mirjalili (2015). Moths fly by positioning at a fixed angle according to the moon to travel long distances on a flat road called transverse orientation. Since the moon is too far away from the moth, the moths can fly straight long distances thanks to this mechanism. When moths come across a man-made artificial light, they try to maintain a light-like angle to fly in a straight line. However, since such a light source is extremely similar compared to the moon, maintaining an angle similar to the light source will not work for moths and even cause a fatal spiral fly path (Fig. 2).

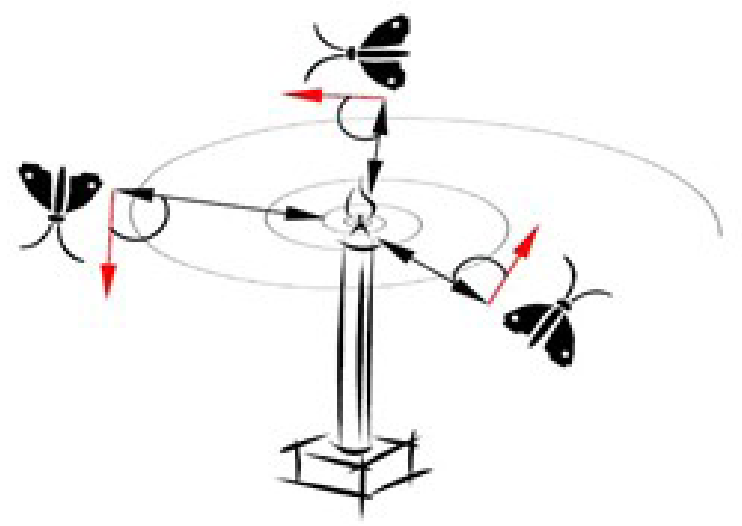

Fig. 2. Spiral flying path around close light sources (Mirjalili, 2015).

The mathematical model of MFO is based on two components, moth and flame. While moths are agents moving around the search area, flames are the best locations. In the population-based MFO algorithm, moths are represented by a matrix (Eq. 3),

$M=\left[\begin{array}{ccccc}m_{1,1} & m_{1,2} & m_{1,3} & \ldots & m_{1, d} \\ m_{2,1} & m_{2,2} & m_{2,3} & \ldots & m_{2, d} \\ \cdot & \cdot & \cdot & \ldots & . \\ \cdot & \cdot & \cdot & \ldots & . \\ m_{n, 1} & m_{n, 2} & m_{n, 3} & \ldots & m_{n, d}\end{array}\right]$

where $m$ is the moth, $n$ is the number of moths and $d$ is the number of variables. AccordingIy, flames can also be represented in a matrix similar to the moth matrix (Eq. 4),

$$
F=\left[\begin{array}{ccccc}
F_{1,1} & F_{1,2} & F_{1,3} & \ldots & F_{1, d} \\
F_{2,1} & F_{2,2} & F_{2,3} & \ldots & F_{2, d} \\
\cdot & \cdot & \cdot & \ldots & \cdot \\
\cdot & \cdot & \cdot & \ldots & \cdot \\
F_{n, 1} & F_{n, 2} & F_{n, 3} & \ldots & F_{n, d}
\end{array}\right]
$$

where $F$ is the flame, $n$ is the number of flames 
Table 2.

MFO algorithm architecture

\begin{tabular}{cc}
\hline Parameters & Value \\
\hline Number of search agents & 20 \\
Maximum number of iterations & 30 \\
Run Number & 100 \\
\hline
\end{tabular}

and $d$ is the number of variables. The MFO algorithm performs with a triple mechanism as shown below.

$\mathrm{MFO}=(\mathrm{I}, \mathrm{P}, \mathrm{T})$

(5)

$\mathrm{I}$ is used to produce a random population of moths and corresponding fitness values, $P$ is a main function that makes the moths move around the search space, and $\mathrm{T}$ is a termination criterion flag.

The position of each moth with regard to a flame is updated as per Eq. 6;

$M_{i}=S\left(M_{i} F_{j}\right)$

The logarithmic spiral is given by Eq. 7;

$S\left(M_{i^{\prime}} F_{j}\right)=D_{i} \cdot e^{b t} \cdot \cos (2 \pi t)+F_{j}$

where $D_{i}$ represents distance of the i-th moth from j-th flame, $b$ is a constant for announcing the shape of the logarithmic spiral, and $t$ is a random number in $[-1 ; 1]$.

$D_{i}=\left|F_{i}-M_{i}\right|$

where $M_{i}$ indicates the $i$-th moth, $F_{i}$ indicates the $\mathrm{j}$-th flame, and $D_{i}$ indicates distance of the $i$-th moth for the j-th flame. The MFO algorithm architecture of this study are presented in Tab. 2.

$$
\text { Objective function }=\sqrt{\left(f_{F R A P}-f_{F R A P, \text { max }}\right)^{2}+\left(f_{T P C}-f_{T P C, \text { max }}\right)^{2}}
$$

\section{Optimization procedure}

In this study, both single and multi-objective optimization procedures were applied. In single-objective optimization problems, only one objective function has maximum or minimum values, while in multi-objective optimization problems, two or more functions are evaluated simultaneously, and optimization is carried out according to the targeted purpose.

Firstly, TPC and FRAP activity models obtained through the ANN method were used as objective functions, and maximum values were obtained through the single objective optimization procedure. Then, both FRAP and TPC were evaluated, and the most appropriate ethanol content and extraction time values, which maximize both objective functions, were obtained with the multi-objective optimization process. The Euclidean distance approach was used in the multi-objective optimization process, to calculate the ideal value of objective functions and to find the closest point to the ideal value (Fig. 3). In Figure 3, the "a" and "b" points show the maximum values of TPC and FRAP, respectively, and the ideal point is formed through the intersection of these points.

The objective function was shown in Eq. 9.;

Minimize: $\|\left(f \overrightarrow{(x)}-z^{i d e a l}\|\|(f \vec{x})-z^{\text {ideal }} \|\right.$

where $f\left(\overrightarrow{x)}\right.$ consists of $f_{F R A P}$ and $f_{T P C}$ and these two functions were the maximum values and are shown in the Eq. 10;

$z^{\text {ideal }}=\left[F R A P_{\max }, T P C_{\max }\right]$

As a result, the ultimate objective function for multi-objective optimization is shown in the Eq. 11 ;

To summarize, this study consisted of three stage: experimental study, modelling and optimization.

\section{RESULTS}

The optimal extraction parameters were determined to get the maximum TPC and FRAP activity values using both of single and multiobjective optimization procedures, respectively. 


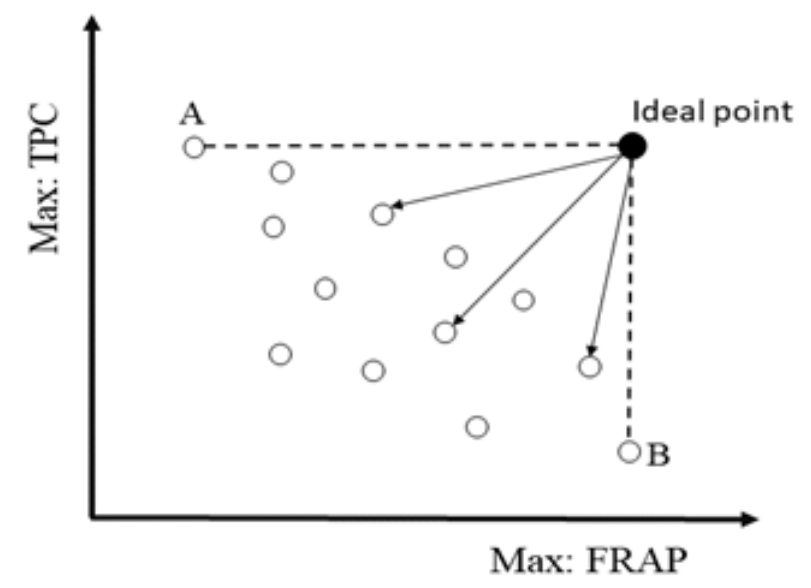

Fig. 3. Euclidean distance approach of this study.

For this purpose, the study was designed as three stages: experimental study, modelling and optimization. Thirty different assays were carried out, and the TPC and FRAP data of ethanol extracts were obtained. TPC and FRAP activities of propolis ethanol extracts are given in Tab. 3.

The highest total phenolic content was 85.35 $\mathrm{mg}$ GAE/g in the extract of experiment number 15, while the lowest amount was $24.19 \mathrm{mg}$ $\mathrm{GAE} / \mathrm{g}$ in the extract of experiment number 3. If the FRAP value is higher, then the antioxidant activity is higher. The highest FRAP value was $657.25 \mu \mathrm{mol} \mathrm{FeSO}_{4} \cdot 7 \mathrm{H}_{2} \mathrm{O} / \mathrm{g}$ in the sample of experiment number 19, and the lowest amount was $227.25 \mu \mathrm{mol} \mathrm{FeSO} \mathrm{FH}_{4} \mathrm{O} / \mathrm{g}$ in the sample of experiment number 4. Furthermore, Duncan's multiple range test found both the TPC and FRAP results of thirty different extractions to significantly different $(p<0.05)$ by; $p$ values of

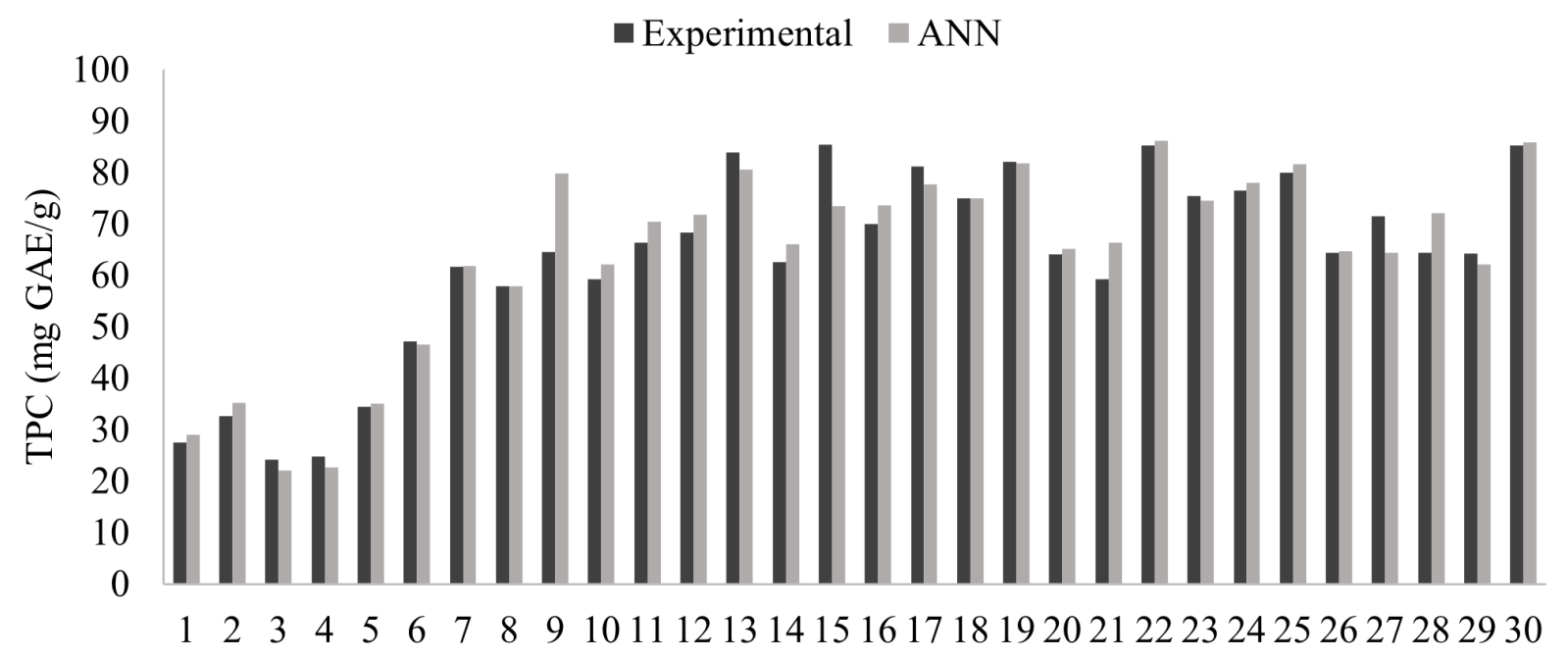

Experiment number

Fig. 4. Experimental and ANN results for TPC.

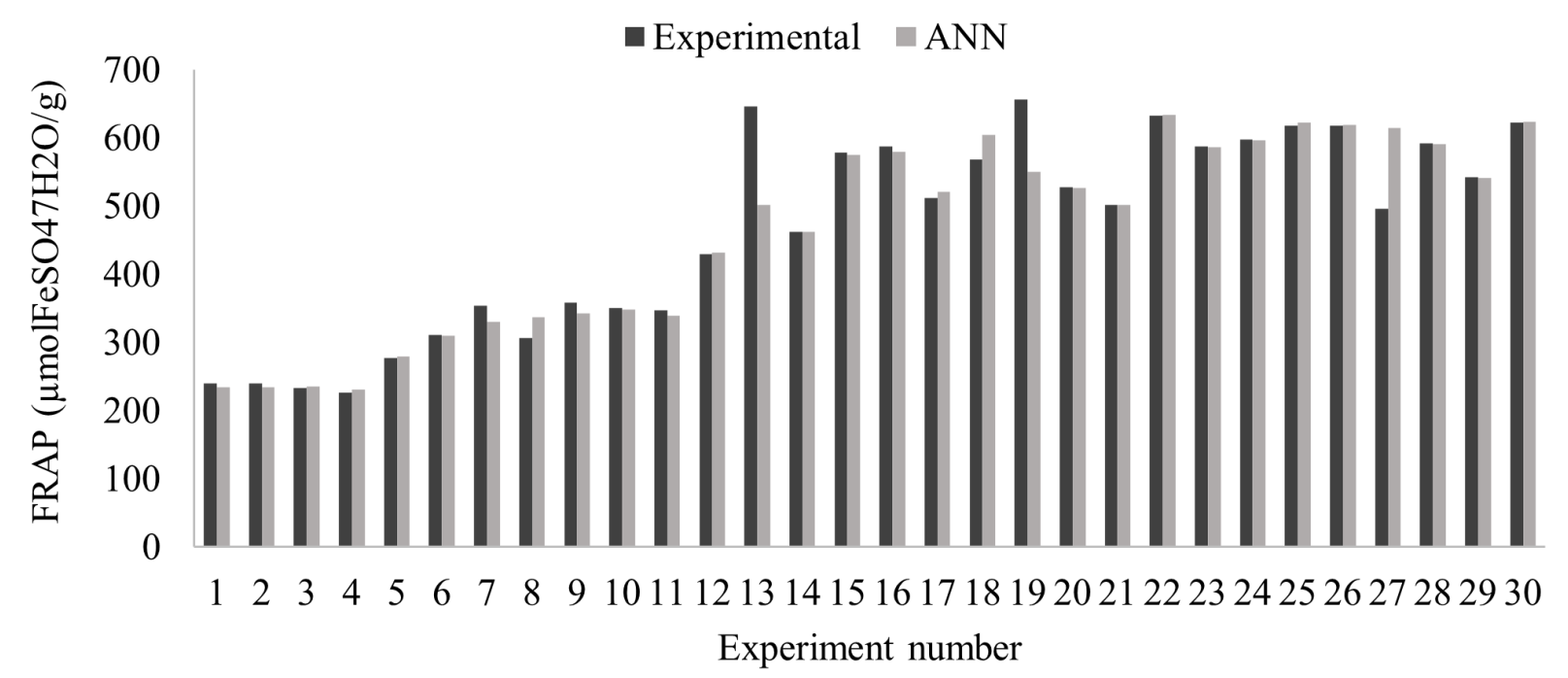

Fig. 5. Experimental and ANN results for FRAP. 
Table 3.

TPC and FRAP activities of propolis ethanol extracts

\begin{tabular}{|c|c|c|c|c|}
\hline $\begin{array}{l}\text { Experiment } \\
\text { number }\end{array}$ & $\begin{array}{c}\text { Ethanol } \\
\text { content (\%) }\end{array}$ & $\begin{array}{l}\text { Extraction time } \\
\text { (h) }\end{array}$ & $\begin{array}{c}\mathrm{TPC} \\
\text { (mg GAE/g) }\end{array}$ & $\begin{array}{c}\text { FRAP } \\
\left(\mu \mathrm{mol} \mathrm{FeSO}{ }_{4} \cdot 7 \mathrm{H}_{2} \mathrm{O} / \mathrm{g}\right)\end{array}$ \\
\hline 1 & 40 & 8 & $27.56 \pm 1.82^{a}$ & $239.85 \pm 6.83^{a}$ \\
\hline 2 & 40 & 10 & $32.69 \pm 0.87^{b}$ & $239.76 \pm 3.82^{a}$ \\
\hline 3 & 40 & 12 & $24.19 \pm 0.68^{a}$ & $233.80 \pm 0.65^{a}$ \\
\hline 4 & 40 & 16 & $24.85 \pm 0.90^{a}$ & $227.25 \pm 2.33^{a}$ \\
\hline 5 & 40 & 20 & $34.39 \pm 0.82^{b}$ & $277.01 \pm 1.21^{\mathrm{b}}$ \\
\hline 6 & 40 & 24 & $47.20 \pm 0.24^{c}$ & $311.79 \pm 2.83^{c}$ \\
\hline 7 & 50 & 8 & $61.64 \pm 0.82^{\text {def }}$ & $353.72 \pm 0.00^{d}$ \\
\hline 8 & 50 & 10 & $57.83 \pm 0.45^{d}$ & $306.93 \pm 0.72^{c}$ \\
\hline 9 & 50 & 12 & $64.51 \pm 2.50^{\mathrm{fgh}}$ & $359.25 \pm 3.75^{d}$ \\
\hline 10 & 50 & 16 & $59.33 \pm 0.19$ de & $350.92 \pm 0.68^{d}$ \\
\hline 11 & 50 & 20 & $66.42 \pm 0.72^{g h i}$ & $346.92 \pm 3.30^{d}$ \\
\hline 12 & 50 & 24 & $68.32 \pm 1.42^{\mathrm{hij}}$ & $430.37 \pm 38.90^{e}$ \\
\hline 13 & 60 & 8 & $83.95 \pm 3.61^{\text {no }}$ & $646.89 \pm 10.04^{\text {nо }}$ \\
\hline 14 & 60 & 10 & $62.53 \pm 3.87^{\mathrm{efg}}$ & $462.13 \pm 5.16^{f}$ \\
\hline 15 & 60 & 12 & $85.35 \pm 0.90^{\circ}$ & $578.34 \pm 1.92^{\mathrm{jk}}$ \\
\hline 16 & 60 & 16 & $70.07 \pm 1.60^{\mathrm{ij}}$ & $587.76 \pm 3.89^{\mathrm{kl}}$ \\
\hline 17 & 60 & 20 & $81.14 \pm 0.09^{\text {no }}$ & $512.79 \pm 9.11^{\mathrm{gh}}$ \\
\hline 18 & 60 & 24 & $74.95 \pm 0.69^{k l}$ & $568.41 \pm 2.03^{j}$ \\
\hline 19 & 70 & 8 & $82.06 \pm 4.46^{\text {по }}$ & $657.25 \pm 2.44^{\circ}$ \\
\hline 20 & 70 & 10 & $64.04 \pm 4.32^{\mathrm{fgh}}$ & $527.87 \pm 17.85^{\mathrm{hi}}$ \\
\hline 21 & 70 & 12 & $59.28 \pm 1.28^{\mathrm{de}}$ & $501.61 \pm 3.76^{9}$ \\
\hline 22 & 70 & 16 & $85.31 \pm 3.33^{\circ}$ & $632.80 \pm 1.34 \mathrm{mn}$ \\
\hline 23 & 70 & 20 & $75.49 \pm 3.02^{\mathrm{kl}}$ & $587.75 \pm 7.73^{\mathrm{kl}}$ \\
\hline 24 & 70 & 24 & $76.44 \pm 1.73^{1 \mathrm{~m}}$ & $597.94 \pm 5.31^{\prime}$ \\
\hline 25 & 80 & 8 & $80.01 \pm 2.09 \mathrm{mn}$ & $617.95 \pm 0.00^{\mathrm{m}}$ \\
\hline 26 & 80 & 10 & $64.34 \pm 0.18^{\mathrm{fgh}}$ & $618.87 \pm 13.44^{m}$ \\
\hline 27 & 80 & 12 & $71.56 \pm 0.477^{j k}$ & $495.96 \pm 11.879$ \\
\hline 28 & 80 & 16 & $64.45 \pm 3.01^{\mathrm{fgh}}$ & $591.99 \pm 11.57 \mathrm{kl}$ \\
\hline 29 & 80 & 20 & $64.28 \pm 6.16^{\mathrm{fgh}}$ & $543.13 \pm 9.23^{i}$ \\
\hline 30 & 80 & 24 & $85.25 \pm 2.24^{\circ}$ & $623.19 \pm 14.57^{\mathrm{m}}$ \\
\hline
\end{tabular}

Means followed by different letter(s) differ significantly at $p<0.05$ (Duncan's multiple range test)

the test for homogeneity variances of TPC and FRAP were 0.032 and 0.000 , respectively.

The process of determining the weight values of neurons connections in ANN, called "training the network", starts with the creation of training, validation and test data. These data sets are created through random selections from the entire data set. The learning algorithms,
Levenberg-Marquardt (LM) and Scaled Conjugate Gradient (SCG), were employed. All values between 1 and 20 were tried as hidden neurons to obtain the best model. Among the potential ANN structures predicting the TPC and FRAP activity of the extracts, the best ones were determined according to their performance. The models using the LM learning 
Table 4.

Performance of the best models

\begin{tabular}{cccccc}
\hline $\begin{array}{c}\text { Studied } \\
\text { assay }\end{array}$ & $\begin{array}{c}\text { Performance of } \\
\text { model }\end{array}$ & Training & Validation & Test & All \\
\hline & MAPE & 4.51 & 4.48 & 8.19 & 5.12 \\
TPC & MSE & 17.02 & 6.46 & 51.67 & 21.74 \\
& $\mathrm{R}^{2}$ & 0.97 & 0.99 & 0.96 & 0.96 \\
& MAPE & 1.41 & 0.69 & 9.23 & 2.45 \\
FRAP & MSE & 81.91 & 12.73 & 3929.23 & 624.12 \\
activity & $\mathrm{R}^{2}$ & 0.99 & 0.99 & 0.96 & 0.98
\end{tabular}

Table 5.

The optimum extraction parameters obtained from single objective optimization

\begin{tabular}{ccccc}
\hline Assay & $\begin{array}{c}\text { Ethanol content } \\
(\%)\end{array}$ & Extraction time (h) & Estimated value & Unit \\
\hline TPC & 57.50 & 13.96 & 91.19 & $\mathrm{mg} \mathrm{GAE} / 9$ \\
FRAP & 72.03 & 18.04 & 673.05 & $\mu \mathrm{mol} \mathrm{FeSO}_{4} \mathrm{7H}_{2} \mathrm{O} / 9$ \\
\hline
\end{tabular}

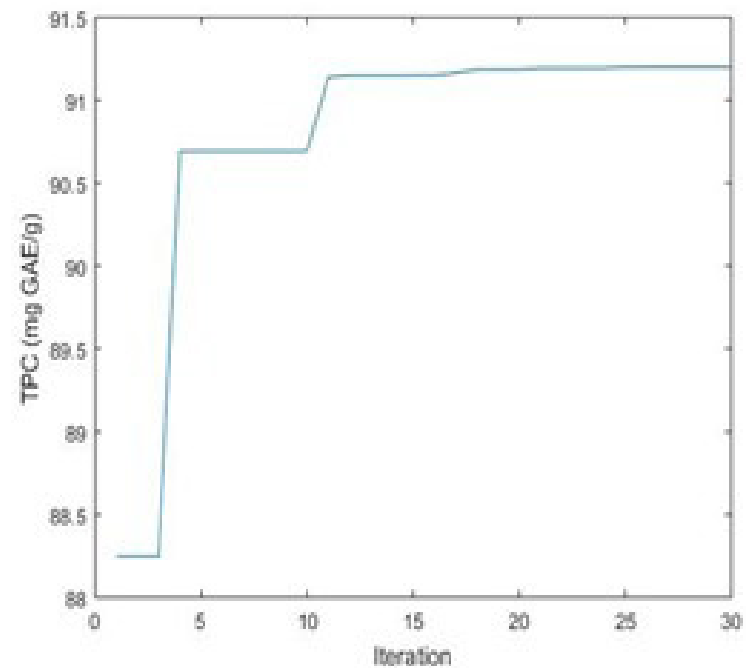

Fig. 6. Optimization course for TPC.

algorithm achieved the best performance for both TPC and FRAP. Thus, the best models were 2-5-1 and 2-5-1 architecture for the TPC and FRAP activity of extracts, respectively. The performances of the best models are presented in Tab. 4.

Experimental and ANN results for the TPC and FRAP activity of propolis ethanol extracts are shown in Figures 4 and 5, respectively. They show how close the predicted value of ANN models and the experimental results are for both studied parameters. The obtained data

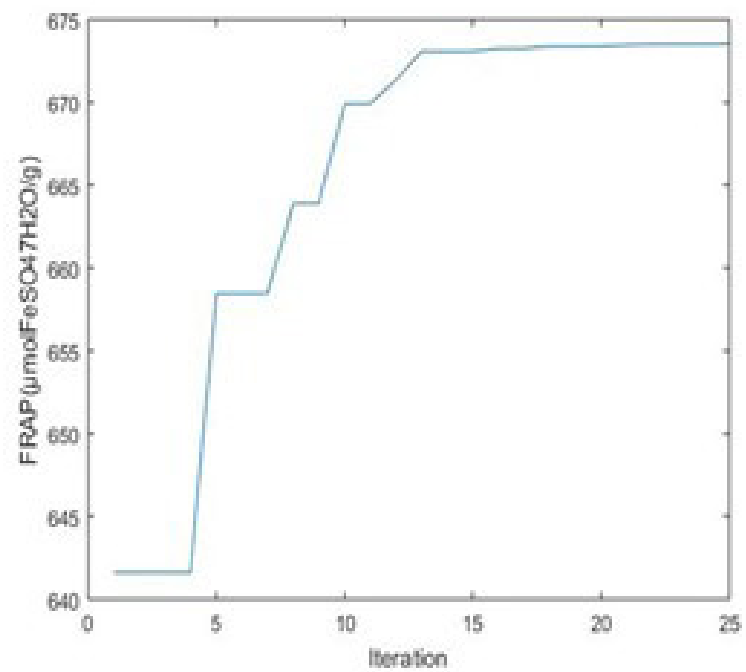

Fig. 7. Optimization course for FRAP.

from assays were modelled and the best models were chosen. Then, optimization procedure was the performed with the MFO algorithm. The best ANN models were used as the objective function. The optimum extraction parameters obtained from single objective optimization are shown in Tab. 5.

Optimum extraction parameters for TPC were found to be $57.50 \%$ ethanol content and 13.56 $\mathrm{h}$ extraction time with the $91.19 \mathrm{mg} \mathrm{GAE} / \mathrm{g}$ value. According to the MFO algorithm results, $72.03 \%$ ethanol content and $18.04 \mathrm{~h}$ extraction 
Table 6.

The optimum extraction parameters obtained from multi-objective optimization

\begin{tabular}{ccccc}
\hline Objective & $\begin{array}{c}\text { Ethanol } \\
\text { content }(\%)\end{array}$ & $\begin{array}{c}\text { Extraction time } \\
(\mathrm{h})\end{array}$ & $\begin{array}{c}\mathrm{TPC} \\
(\mathrm{mg} \mathrm{GAE} / \mathrm{g})\end{array}$ & $\begin{array}{c}\text { FRAP } \\
\left(\mu \mathrm{mol} \mathrm{FeSO}_{4} \mathrm{FH}_{2} \mathrm{O} / \mathrm{g}\right)\end{array}$ \\
\hline $\begin{array}{c}\text { Max. TPC } \\
\text { Max. FRAP }\end{array}$ & 70.03 & 16.93 & 83.35 & 667.26 \\
\hline
\end{tabular}

time reached the maximum FRAP values of ethanolic extracts of propolis with $673.05 \mu \mathrm{mol}$ $\mathrm{FeSO}_{4} \cdot 7 \mathrm{H}_{2} \mathrm{O} / \mathrm{g}$ value. The optimization course for TPC and FRAP are shown in Fig. 6 and 7, respectively.

The objective value for the first iteration was found to be $88.28 \mathrm{mg} \mathrm{GAE/g}$ for the TPC activity of propolis ethanolic extracts. The objective value increased for subsequent iterations. In the $25^{\text {th }}$ iteration, the objective value was stable reaching $91.19 \mathrm{mg} \mathrm{GAE} / \mathrm{g}$, and the final value was obtained. The objective value for the first iteration was found to be $641.07 \mu \mathrm{mol} \mathrm{FeSO} \mathrm{FH}_{4} \mathrm{H} / \mathrm{g}$ for FRAP activity of ethanolic extracts of propolis. In the 20th iteration, the objective value reached 673.05 $\mu \mathrm{mol} \mathrm{FeSO}_{4} \cdot 7 \mathrm{H}_{2} \mathrm{O} / \mathrm{g}$ and then did not show an increase in the subsequent iterations. The optimum extraction parameters obtained from multi-objective optimization are shown in Tab. 6. In this study, the optimum extraction parameters obtained from multi-objective optimization procedure were $70.03 \%$ ethanol content and $16.93 \mathrm{~h}$ extraction time, and the highest TPC and FRAP values were $83.35 \mathrm{mg} \mathrm{GAE} / \mathrm{g}$ and $667.26 \mu \mathrm{mol} \mathrm{FeSO} \mathrm{FH}_{2} \mathrm{O} / \mathrm{g}$, respectively.

\section{DISCUSSION}

Bees use propolis in honeycombs to protect their hive, create aseptic settlements, repair damage and create a heat insulator. Phenolic and flavonoid compounds are the main components responsible for the bioactivity properties of propolis. In this study, the TPC values of examined extracts ranged from 24.19 to 85.31 mg GAE/g (Tab. 3). Socha et al. (2015) found that the total phenolic content in different regions of Poland ranged from 150.05 to $197.14 \mathrm{mg}$ GAE/g. In our study, the total phenolic content of Turkish propolis was lower than that of the studied propolis samples. This can be thought to be due to the difference in vegetation. Another study reported that the total phenolic contents ranged from 10.94 to $79.23 \mathrm{mg}$ GAE/g in 95\% ethanolic extract of propolis obtained from different regions of Azerbaijan (Can et al., 2015). FRAP assay is the most commonly used method to specify total antioxidant capacity. In the study, FRAP values of studied extracts ranged from 227.25 to $657.25 \mu \mathrm{mol} \mathrm{FeSO}{ }_{4} \cdot 7 \mathrm{H}_{2} \mathrm{O} / \mathrm{g}$. Aliyazicioglu et al. (2013) reported that the FRAP values of methanolic propolis samples have changed between 182.12 and 325.47 $\mu \mathrm{M}$ Trolox/g in various Anatolian areas of Turkey. Mihai et al., (2011) reported that the total phenolic content was 31.22 to $61.34 \mathrm{~g}$ GAE/100 g and FRAP values 0.74 to $2.37 \mathrm{Fe}(\mathrm{II}) \mathrm{SO}_{4} / \mathrm{g}$ in Transylvania propolis samples.

The MAPE value provides information about the predictive ability of the ANN model. A low MAPE value means that the model's prediction ability is superior. A model with a MAPE value of $5.0 \%$ can be concluded to estimate the studied data with $95.0 \%$ accuracy. In this study, MAPE values of the best models were 5.12 and $2.45 \%$ for the TPC and FRAP activity values of propolis ethanol extracts, respectively.

MSE values of the best model were $21.74 \mathrm{mg}$ GAE/g and $624.12 \mu \mathrm{mol} \mathrm{FeSO}_{4} \cdot 7 \mathrm{H}_{2} \mathrm{O} / \mathrm{g}$ for TPC and FRAP activity, respectively. If the MSE value is not compared with the similar studies, it may give misleading results, as in this study. Since the MSE value is related to the results of the studied assay, the higher value of assays will cause the MSE value to be higher. In this study, comparing the MSE values would not be the right approach since the FRAP values were five to eight times higher than the TPC values. It can be concluded that the closer $\mathrm{R}^{2}$ (coeffi- 
cient of determination) value to 1 means that the predictive success of the model is greater. In this study, $\mathrm{R}^{2}$ values were determined to be 0.967 and 0.985 for TPC and FRAP activities, respectively. It can be deduced that, under the same extraction conditions, when ANN is used, the model predicts the TPC values somewhat more accurately than the FRAP activity values. Useful mathematical models have been created to separate bee products by origin and based on selected physical-chemical parameters, in many countries. Furthermore, researchers have investigated the potential of ANNs as an analytical alternative to such traditional modelling techniques as response surface methodology and multiple regression analysis, the rheological behavior of food that are limited by strict assumptions of normality, variable independence, homogeneity and linearity. They discovered that ANN could predict rheological properties with high accuracy.

Optimum extraction parameters were determined as: $57.50 \%$ ethanol content and $16.53 \mathrm{~h}$ extraction for maximum TPC; $72.03 \%$ ethanol content and 18.04 h extraction time for FRAP, using single objective optimization; also $70.03 \%$ ethanol content and $16.93 \mathrm{~h}$ extraction time by multi-objective optimization procedure. Yingjuan et al. (2007) reported that the optimum processing for ultrasound extraction was $79.51 \%$ ethanol, 19.31 min extraction time, 538.38 W extracting power, 39.48:1 liquid to propolis for the maximum flavones of propolis. Kim et al. (2009) notified that an ethanol concentration of $72-82 \%$ and an extraction time of 2.2-3.3 among the 1 and 5 hour extraction time were optimal for the preparation of propolis extracts. Zhao et al. (2012) optimized the optimal microwave-assisted extraction conditions for total flavonoids as follows: 70 $\mathrm{s}$ microwave treatment at $282 \mathrm{~W}$ followed by extraction with $80 \%$ ethanol aqueous solution at a solvent-to-solid of $25 \mathrm{~mL} / \mathrm{g}$ and 77 for $12 \mathrm{~h}$. Oldoni et al. (2015) also optimized the extraction parameters as time (45 min), temperature $\left(70^{\circ} \mathrm{C}\right)$ and concentration of ethanol (80\%) for TPC and DPPH activity of propolis.

In this study the optimal extraction parameters of propolis ethanolic extracts for the maximum TPC and FRAP activity values were investigated with the use of both single and multi-objective optimization procedures. For this purpose, the study was designed as three stages: experimental study, modelling and optimization. As a result, integration ANN and MFO algorithm methods can be used for research in the field of chemistry with a high accuracy saving cost, chemical, time and effort.

\section{ACKNOWLEDGEMENTS}

We confirm that there are no known conflicts of interest. We confirm that the manuscript has been read and approved by all named authors and that there are no other persons who satisfied the criteria for authorship but are not listed.

\section{REFERENCES}

Aliyazicioglu, R., Sahin, H., Ertürk, O., Kolayli, S. (2013). Properties of phenolic composition and biological activity of propolis from Turkey. International Journal of Food Properties, 16(2), 277-287. DOl: 10.1080/10942912.2010.551312

Bankova, V.S., De Castro, S.L., Marcucci, M.C. (2000). Propolis: recent advances in chemistry and plant origin. Apidologie, 37(1), 3-15. DOl: 10.1051/ apido:2000102

Benzie, I.F., \& Strain, I.J. (1996). The ferric reducing ability of plasma (FRAP) as a measure of "antioxidant power": the FRAP assay. Analytical Biochemistry, 239(1), 70-76. DOl: 10.1006/abio.1996.0292

Can, Z., Yildiz, O., Sahin, H., Asadov, A., Kolayli, S. (2015). Phenolic profile and antioxidant potential of propolis from Azerbaijan. Mellifera, 15(1), 16-28.

Casquete, R., Castro, S.M., Jácome, S., Teixeira, P. (2016). Antimicrobial activity of ethanolic extract of propolis in "Alheira", a fermented meat sausage. Cogent Food Agriculture, 2(1), 1125774. DOl: 10.1080/23311932.2015.1125774 
Chi, L.C., \& Tang, T.C. (2005). Artificial neural networks in reorganization outcome and investment of distressed firms: the Taiwanese case. Expert Systems with Applications, 29(3), 641-652. DOl: 10.1016/j.eswa.2005.04.021

Haykin, S. (1994). Neural networks: a comprehensive foundation. Upper Saddle River, NJ, USA: Prentice Hall PTR.

ladnut, A.K., Mamoon, P., Thammasit, S., Pawichai, S., Tima, K.... Tragoolpua K. (2019). In vitro antifungal and antivirulence activities of biologically synthesized ethanolic extract of propolis-loaded PLGA nanoparticles against Candida albicans. EvidenceBased Complementary Alternative Medicinal, Article ID 3715481, 14 pages. DOl: 10.1155/2019/3715481

Jonaidi Jafari, N., Kargozari, M., Ranjbar, H., Rostami, H., Hamedi, H. (2018). The effect of chitosan coating incorporated with ethanolic extract of propolis on the quality of refrigerated chicken fillet. Journal of Food Processing and Preservation, 42(1), 1-8. D0l: 10.1111/jfpp.13336

Jothiprakash, V., \& Garg, V. (2009). Reservoir sedimentation estimation using artificial neural network. Journal of Hydrologic Engineering, 14(9), 1035-1040. DOl: 10.1061/(ASCE)HE.19435584.0000075

Kim, S.H., Kim, I.H., Kang, B.H., Lee, K.H., Lee, S.H., Lee, D.S., ... Lee J.M. (2009). Optimization of ethanol extraction conditions from propolis (a bee product) using response surface methodology. Korean Journal Food Preservation, 16(6), 908-914.

KIhar, G.T., Isola, J.V., Da Rosa, C.S., Giehl, D.Z., Martins, A.A., Bartmer, M.E., Segabinazzi, L.R. (2019). Antimicrobial activity of the ethanolic extract of propolis against bacteria that cause mastitis in cattle. Biotemas, 32(1), 1-10.

Li, S., Zhao, Y.Y., Chen, X.P. (2012). Optimization of microwave-assisted extraction of flavonoids from propolis by response surface methodology. Food Science, 78.
Mihai, C.M., Mărghitaș, L.A., Dezmirean, D.S., Bărnuțiu, L. (2011). Correlation between polyphenolic profile and antioxidant activity of propolis from Transylvania. Scientific Papers: Animal Science and Biotechnologies, 44(2), 100-103.

Mirjalili, S. (2015). Moth-flame optimization algorithm: A novel nature-inspired heuristic paradigm. Knowledge-Based Systems, 89, 228-249. DOl: 10.1016/j.knosys.2015.07.006

Moreno, M.N., Isla, M.l., Sampietro, A.R., Vattuone, M.A. (2000). Comparison of the free radicalscavenging activity of propolis from several regions of Argentina. Journal of Ethnopharmacology, 77(12), 109-114. DOl: 10.1016/\$0378-8741(99)00189-0

Nichitoi, M.M., Josceanu, A.M., Daniela, R., Isopescu, G.l., Lavric, V. (2019). Romanian propolis extracts: characterization and statistical analysis and modelling. U.P.B. Scientific Bulletin Series B: Chemistry and Materials Science, 81(4), 149-162.

Oldoni, T.L.C., Oliveira, S.C., Andolfatto, S., Karling, M., Calegari, M.A., Sado, R.Y.,... Lima, V.A. (2015). Chemical characterization and optimization of the extraction process of bioactive compounds from propolis produced by selected bees Apis mellifera. Journal of Brazilian Chemical Society, 26(10), 2054-2062. DOl: 10.5935/0103-5053.20150186

Rivero-Cruz, J.F., Granados-Pineda, J., PedrazaChaverri, J., Pérez-Rojas, J.M., Kumar-Passari, A., DiazRuiz, G., Rivero-Cruz, B.E. (2020). Phytochemical constituents, antioxidant, cytotoxic, and antimicrobial activities of the ethanolic extract of mexican brown propolis. Antioxidants, 9(1), 70. DOl: 10.3390/antiox9010070

Slinkard, K., \& Singleton, V.L. (1977). Total phenol analysis: automation and comparison with manual methods. American Journal of Enology and Viticulture, 28, 49-55.

Smith, A.E. (1994). X-bar and R control chart interpretation using neural computing. Internatioanal Journal of Production Research, 32(2), 309-320. D0l: 10.1080/00207549408956935 
Socha, R., Gałkowska, D., Bugaj, M., Juszczak, L. (2015). Phenolic composition and antioxidant activity of propolis from various regions of Poland. Natural Products Research, 29(5), 416-422. DOl: 10.1080/14786419.2014.949705

Wang, N., Ye, M., Wang, C., Shi, Y., Zhang, J. (2009). Optimizing ultrahigh pressure extracting technique for flavones from propolis. Acta Agriculturae BorealiOccidentalis Sinica, 3.

Yingjuan, F. (2007). Optimization of extraction processing of propolis flavones by ultrasound [u]. Science Technology Food Industrial, 5.
Yuan, J., Lu, Y., Abula, S., Hu, Y., Liu, J., Fan, Y., ... Liu, C. (2013). Optimization on preparation condition of propolis flavonoids liposome by response surface methodology and research of its immunoenhancement activity. Evidence-Based Complementary Alternative Medicinal, Article ID 50573, 8 pages. DOl: 10.1155/2013/505703

Zhao, Y., Tian, W., Guo, Z., Gao, L., Peng W. (2012). Optimization of ethanol extraction technology from propolis by response surface methodology. Journal Agricultural Science and Technology, 14(3), 85-93. 